\title{
Pattern of Pediatric Morbidity in Hospital Admitted Patients in Western Region of Nepal
}

\author{
Adhikari $\mathbf{P}^{1^{*}}$, Kandel $\mathrm{D}^{2}$, Shrestha $\mathrm{U}^{2}$ \\ ${ }^{1}$ Intern, ${ }^{2}$ MBBS $3^{\text {rd }}$ year, Gandaki Medical College \& Teaching Hospital, Pokhara, Nepal
}

\author{
Keywords \\ Child health, Morbidity, \\ Pediatric patients. \\ Corresponding author \\ *Dr. Purushottam Adhikari \\ Intern, Gandaki Medical College \& \\ Teaching Hospital, Pokhara, Nepal \\ Email: puru.ad12@gmail.com
}

\begin{abstract}
Background: Pediatric age group comprises the important fraction of hospital admissions in our health care settings and it is the major challenge to address in the developing countries like ours. This study was carried out to find out the significant epidemiological trends and disease patterns of the admitted children in a pediatric ward.
\end{abstract}

Methods: This retrospective study was carried out by reviewing hospital records of the patients admitted in the pediatric ward from July 2015 to January 2016 in Gandaki Medical College Teaching Hospital. The disease pattern was analyzed on the basis of age, sex, final diagnosis of the disease, duration of hospital stay and months of admission.

Results: Among the 1348 admitted children during the study period, majority were males (65\%) and below five years (74\%). Lower respiratory tract infections $(30 \%)$, enteric fever $(10 \%)$ and acute gastroenteritis $(7.7 \%)$ were the three major causes for admission. The mean days of hospital stay was 4.43 and maximum number of children was admitted during August/September.

Conclusion: Infectious diseases are the major cause for morbidity and more were during the rainy season.

\section{INTRODUCTION}

Pediatric morbidity is one of the major health challenges of the developing and underdeveloped nations. It comprises one of the important fractions of hospital admission in our settings. As per the World Health Organization factsheets, around 5.9 million children under the age of 5 years died in 2015 and more than half them were due to those conditions that could either be prevented or treated with access to simple, affordable interventions ${ }^{1}$.

Nepal has the infant mortality rate of 32 per 1000 live births and under-5 mortality rate of 39 per 1000 live births. It has decreased in recent decades but still long way to meet the Sustainable Development Goals target for 2017 to reduce under-5 mortality to 28 per 1000 live births ${ }^{2}$.

This study has been planned with objective to analyze the demographic characteristics, disease profile and epidemi- ological trends of the pediatric patients admitted in Gandaki Medical College Teaching Hospital.

Similar studies have been conducted in other medical colleges and hospitals of $\mathrm{Nepal}^{3,4,5}$, but quite earlier. Also there has been paucity of this type of research around Western hilly region of Nepal. This would help to find out the burden of particular childhood disease in this region and it would promulgate the necessity for policies and plan to address the preventive approach for that particular diseases.

\section{METHODS}

This was a retrospective study carried out in the Gandaki Medical College Teaching Hospital. The hospital records of the patients admitted in the pediatric ward from July 2015 to January 2016 was taken from record section. Age, 
sex, address, duration of hospital stay and final diagnosis was noted. Patients were admitted from the pediatric outpatient department as well as from Emergency Department and managed by Medical Officers and Pediatricians. Final diagnosis of disease was recorded in accordance to International Classification of Disease. Neonates admitted in neonatal intensive care unit and other pediatric patients admitted in pediatric intensive care unit were not included in study. The data was entered in Microsoft Excel and analyzed.

Ethical clearance for the study was taken from Institutional Review Board of Gandaki Medical College Teaching Hospital.

\section{RESULTS}

A total of 1348 patients were admitted in the ward during the study period. Among them 474 (35\%) were females whereas 874 (65\%) were males as shown in Figure 1.

Fig 1: Gender wise distribution of the patients

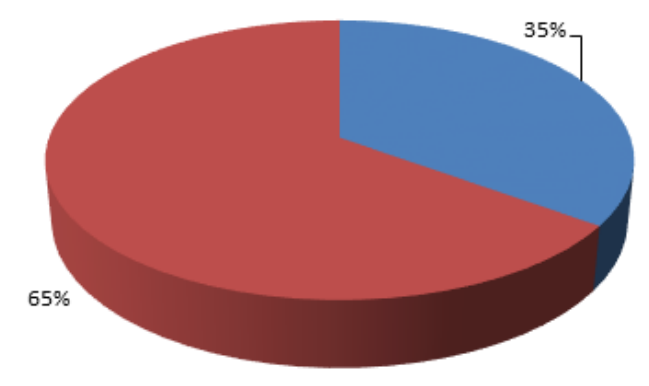

More than half of the patients are below the age of 5 years as shown in Figure 2.

Fig 2: Age wise distribution of the patients
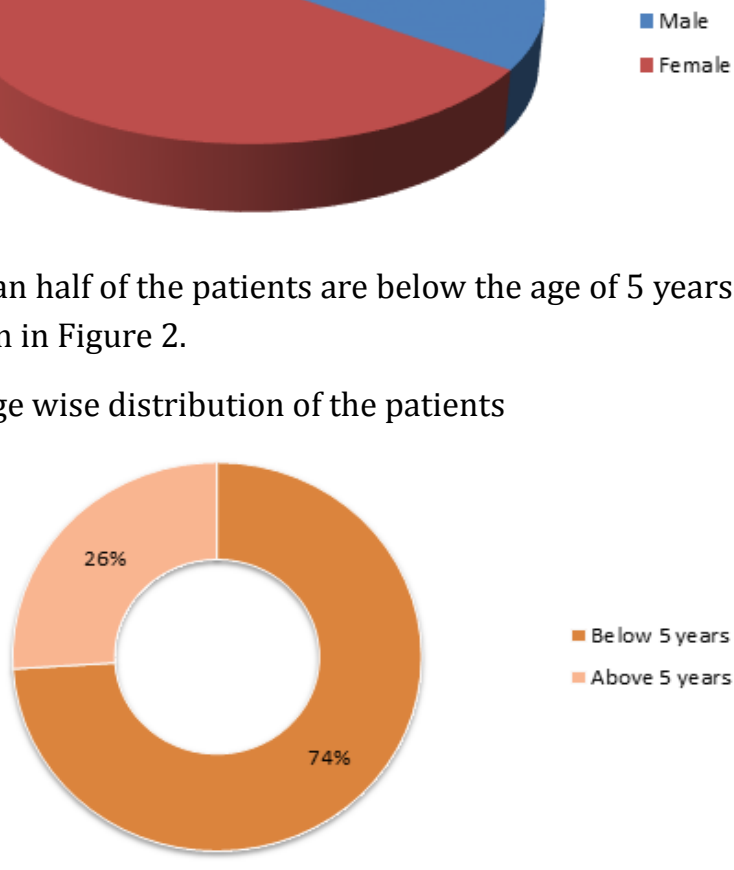

The most commonly involved system among those admitted is respiratory system followed by gastrointestinal and renal as shown in figure 3. Among the respiratory system diseases, lower respiratory tract infection including pneumonia $(413 ; 30 \%)$ was the most common cause of admission followed by acute bronchiolitis $(68 ; 5 \%)$ and bronchial asthma (46; 3.4\%). Enteric fever $(137 ; 10 \%)$ and acute gastroenteritis $(105 ; 7.7 \%)$ were the major gastrointestinal diseases for admission. Similarly, urinary tract infections $(43 ; 3 \%)$ and post streptococcal glomerulonephritis $(20 ; 1.4 \%)$ accounted for the important renal diseases. Febrile seizure $(54 ; 4 \%)$ and hematological disorders (15; $1.1 \%$ ) were the significant diseases involving central nervous system and cardiovascular diseases respectively.

Fig 3: System wise involvement of the disease

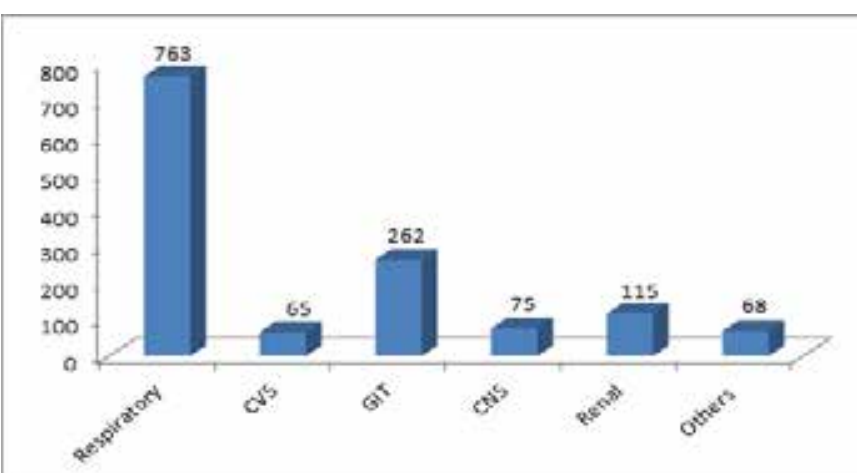

Similarly, all the admitted patients stayed in hospital for one day in minimum and up to maximum of 23 days. The detail of duration of hospital stay is shown in Table 1.

Table 1: Duration of hospital stay

\begin{tabular}{|c|c|}
\hline $\begin{array}{c}\text { Duration of hospital stay } \\
\text { (Days) }\end{array}$ & No of patients \\
\hline $1-3$ & 338 \\
\hline 4 & 324 \\
\hline 5 & 443 \\
\hline 6 and more & 243 \\
\hline
\end{tabular}

During the six months of study period the maximum of admissions were during the month of August/September.

Fig 4: Month wise distribution of patients

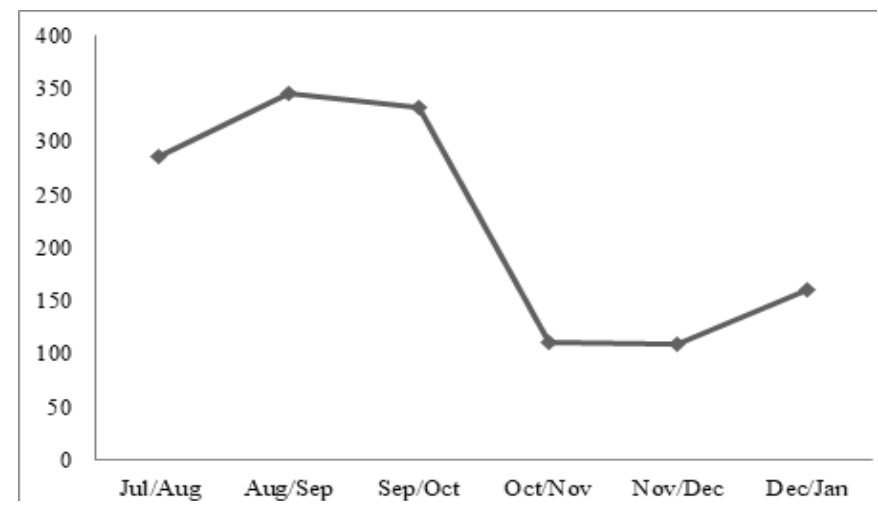

\section{DISCUSSION}

During the study period male children were more in number $(65 \%)$ than female children $(35 \%)$ admitted in pediatric ward for the treatment with male: female ratio of 1.84 . 
This finding is similar to the other studies conducted in the Medical College and Zonal Hospital of Nepal ${ }^{3,4,5}$. This may be due to the preference of male child to bring hospital as soon as possible in our society. Similarly, children of less than five years are more in number (74\%) than the age group more than five years among the admitted ones in our study.

Respiratory system was the most commonly involved with respiratory tract infection including pneumonia being the major cause of morbidity of children in our scenario. Enteric fever and acute gastroenteritits involving the gastrointestinal system were the subsequent causes for the admission. These findings are in consistent with the similar studies conducted in other set up including the one conducted in Bangladesh by Hasan et $a l^{4,5,6}$. The national data from recent Annual Health Report published by Department of Health Services also shows the acute respiratory infection being the most common cause of childhood diseases followed by acute diarrhea ${ }^{7}$. The socioeconomic status of the people, lack of education, sanitation and poor access to health care facilities are supposed to be the causes for these infectious diseases being the major reason for hospital admission. A study by Rice et al published in WHO Bulletin suggests malnutrition as the important underlying cause for the mortality associated with infectious disease in children in developing countries ${ }^{8}$.

Similarly, the maximum number of patients stayed for five days in the hospital. A patient of lower respiratory tract infection stayed for 23 days. The mean days of hospital stay for the patients were 4.43 days.

During the six months of our study, maximum number of admission was in August/September. This finding was similar with the study conducted in a Zonal Hospital of Ne$\mathrm{pal}^{4}$. This may be due to the rainy season favoring for the more diarrhea and enteric fever cases.

The results in our study came up with the brief epidemiological trend of the disease pattern with which the children are admitted in the Hospital of Western Region of Nepal. Though it's the limitation of our study that we did only the retrospective analysis of the cases for a period of six months, this finding could be the basis for policy makers to address the current challenges in the management of childhood illness.

\section{CONCLUSIONS}

Our study concluded that lower respiratory infections and acute gastroenteritis are the main cause for the hospital admission for the children living in the Western hilly re- gion of Nepal. Males were more in number to be admitted in Hospital and the age groups of less than five years were more predisposed for admission than the elder age groups. August/September is the period for the maximum number of admissions.

\section{Acknowledgement}

Authors would like to thank to the faculties of Department of Pediatrics, Gandaki Medical College Teaching Hospital for their support, guidance and suggestion during the course of study. Similarly, we are grateful to medical record section of Gandaki Medical College for providing the necessary record books for the study.

\section{REFERENCES}

1. Children: reducing mortality [Internet]. World Health Organization. World Health Organization; [cited 2017 Nov 17]. Available from: http://www.who.int/mediacentre/factsheets/fs178/en/

2. Ministry of Health, Nepal; New ERA; and ICF. 2017. Nepal Demographic and Health Survey 2016: Key Indicators. Kathmandu, Nepal: Ministry of Health, Nepal.

3. Upadhyay S, Sharma A, Rijal P, Shrestha S. Review of Paediatrics In-Patient at Nepal Medical College and Teaching Hospital. J Nepal Paedtr Soc. 2011; 31(1): 2529.

4. Paudel KM, Sharma S. Review of Paediatrics Inpatient at a Zonal Hospital. J Nepal Paediatr Soc. 2012; 32(3): 239-244.

5. Adhikari J, Belbase M, Bahl L. Demographic Profile and Childhood Morbidity Pattern in Western Nepal Journal of Nepalgunj Medical College 2014; 12(2): 20-23.

6. Hasan MS, Barua SK, Mahmud MN, Kamal A, Enayetullah M, Karim MR. Disease profile and death pattern among children admitted in a Medical College Hospital. Bangladesh Journal of Child Health. 2012; 36(2): 66-70.

7. Department of Health Services. Annual report (2015/2016), 22 ed. Kathmandu, Nepal: Government of Nepal, Ministry of Health; 2017.

8. Rice AL, Sacco L, Hyder A, Black RE. Malnutrition as an underlying cause of childhood deaths associated with infectious diseases in developing countries. Bull World Health Organ. 2000; 78(10): 1207-21. 